\title{
Abnormal Placental Findings Associated with Non-reassuring Fetal Monitoring and Excellent Neonatal Outcomes
}

\author{
Gary Ventolini ${ }^{1}$, Shanthi Ramesh ${ }^{1}$, Sheela Barhan ${ }^{1}$, Ran Neiger ${ }^{2}$ \\ ${ }^{1}$ Wright State Physicians Boonshoft School of Medicine Department of Obstetrics and Gynecology, Dayton Ohio, USA; ${ }^{2}$ Perinatal \\ Partners, Miami Valley Hospital Berry Building, Maternal Fetal Medicine, Dayton Ohio, USA. \\ Email: Gary.ventolini@wright.edu
}

Received February $29^{\text {th }}, 2011$; revised April 27 $7^{\text {th }}, 2011$; accepted May $12^{\text {th }}, 2011$.

\begin{abstract}
Objective: Obstetricians, Neonatologists, and Pathologists have studied gross histological analysis of human placentas in search of specific alterations in placental functions that can be correlated with neonatal outcomes. Our study assessed the prevalence of abnormal placental findings associated with non-reassuring fetal monitoring in labor requiring emergent instrumental or cesarean delivery, followed by an excellent neonatal outcome. Study Design: One hundred consecutive emergency deliveries, instrumental or cesarean, performed due to non-reassuring fetal monitoring while in labor were retrospectively evaluated. All patients were low-risk for obstetric complications, and had a singleton, term pregnancy. They had a normal antenatal routine testing and a normal anatomy ultrasound scan at 20 to 22 weeks gestation. Results: There were 35 placentas (35\%) with gross placental anomalies at the delivery triage. Additionally 7 placentas (7\%) were reported to be abnormal at the pathology examination. Conclusions: The prevalence of abnormal placental findings in our studied population was $42 \%$.
\end{abstract}

Keywords: Abnormal Placental Findings, Excellent Neonatal Outcomes, Non-Reassuring Fetal Monitoring

\section{Introduction}

Obstetricians, Neonatologists, and Pathologists have studied gross and histological analysis of human placentas in search of specific alterations in placental function that can be correlated with neonatal outcomes. The placenta provides a third party perspective regarding the pregnancy and many maternal and fetal conditions are evidenced by placental abnormalities [1]. Specific placental pathology is found in pregnancy loss associated with thrombophilia, in many stillbirths and neonatal deaths, and in cases of non-immune hydrops fetalis [2]. Many grossly and histopathological abnormal placentas are, however, not associated with adverse neonatal outcomes. Further attention to placental analysis including more rigorous guidelines for pathologic diagnosis is needed to delineate which abnormal findings are associated with adverse neonatal outcomes.

Per The College of American Pathologists (CAP) guidelines, all human placentas should be inspected and triaged at the delivery room and the abnormal ones should be sent to pathology for a complete examination using specific examination criteria as established by the CAP. As previously determined by Ventolini et al., in a cohort of 88 uneventful deliveries, $42 \%$ of placentas had abnormal findings during pathological evaluation. Thirteen of the abnormal placentas (35.1\%) showed pathology unassociated with fetal compromise. Twenty-four of the placentas $(27.3 \%$ of the total cohort and $64.9 \%$ of the abnormal placentas) showed findings associated with fetal compromoise, all with APGAR scores at birth of greater than or equal to 7 at 1 and 5 minutes. The most common pathologies were marginal cord insertion, chorioamnionitis, and abruption [3].

The purpose of our study was to assess the prevalence of abnormal placental findings associated with non-reassuring fetal monitoring in labor requiring emergent instrumental or cesarean delivery, followed by an excellent neonatal outcome.

\section{Materials and Methods}

One hundred consecutive emergency deliveries, instrumental or cesarean, performed due to non-reassuring fetal monitoring while in labor were retrospectively 
evaluated. The study was approved by the Institutional Review Board and took place at a large tertiary hospital between January 2003 and December 2008. All patients were low-risk for obstetric complications, and had a singleton, term pregnancy. In addition they had a normal antenatal routine testing and a normal anatomy ultrasound scan at 20 to 22 weeks gestation.

The patients were admitted to the hospital in active labor. Their fetal monitoring tracings on admission were all reactive as well as the admission routine prenatal laboratory parameters were within normal limits. Furthermore, on admission history, they recollected having no changes in fetal behavior the 48 hours prior to admission. They were all non-smokers and their urinary drug toxicology screen was negative on admission.

As labor progressed, the patient's fetuses manifested intolerance to labor, characterized by repeat prolonged decelerations and/or repeat late decelerations that required emergent instrumental delivery and/or cesarean delivery. Their fetal intolerance was not preceded by uterine hyperstimulation or by regional anesthesia placement and not fully resolved by fetal intrauterine resuscitation.

All the neonates were delivered with APGAR scores of equal or more than 7 at 5 minutes of birth, normal arterial and venous umbilical blood cord gases and uneventful nursery stay. All the placentas were triaged at the delivery room, the ones revealing any anomaly at gross assessment, were sent to pathology for examination. Statistical analysis was performed with GraphPad Software (GraphPad Software, San Diego, CA)

\section{Results}

Twenty eight patients $(28 \%)$ had an instrumental delivery: 12 deliveries $(12 \%)$ were vacuum assisted and 16 deliveries (16\%) were forceps assisted. Seventy two patients $(72 \%)$ had a cesarean delivery (see Table 1).

There were 35 placentas $(35 \%)$ with gross placental anomalies at the delivery triage. The placental findings were: $7(7 \%)$ had opaque amniotic membranes, $6(6 \%)$ with velamentous cord insertion, $6(6 \%)$ had a long umbilical cord $(105 \mathrm{~cm}), 6(6 \%)$ presented with foul smelling amniotic membranes, $4(4 \%)$ had a short umbilical cord, $4(4 \%)$ with retro placental hemorrhage and $2(2 \%)$ with acute abruption. Additionally 7 placentas (7\%) were reported to be abnormal at the pathology examination as follow: chorioamnionitis, funisitis, and true knots (see Table 2).

\section{Discussion}

The placenta serves as vital resource in evaluating neonatal and maternal outcomes following delivery for non reassuring fetal heart monitoring. The placenta contains nine months of data available that could be gathered through careful pathologic evaluation regarding etiolo
Table 1. Mode of delivery.

\begin{tabular}{lllll}
\hline Instrumental & Patients & $\begin{array}{l}\text { Abnormal } \\
\text { Placentas }\end{array}$ & Normal & $\boldsymbol{P}$ Value \\
\hline Vaccum Assisted & 12 & 4 & 8 & 0.48 \\
Forceps Assisted & 16 & 5 & 11 & 0.35 \\
Cesarean & 72 & 33 & 39 & 0.66 \\
Total & 100 & 42 & 58 & \\
\hline
\end{tabular}

Table 2. Placental findings.

\begin{tabular}{|c|c|c|c|}
\hline $\begin{array}{l}\# \\
\text { Placentas }\end{array}$ & Triage & $\begin{array}{l}\text { Macroscopy } \\
\text { Path }\end{array}$ & $\begin{array}{l}\text { Microscopy } \\
\text { Path }\end{array}$ \\
\hline 6 & $\begin{array}{l}\text { Velamentos } \\
\text { cord insertion }\end{array}$ & Agreed 6 & $\begin{array}{l}2 \text { Fibrin deposits } \\
1 \text { Small infarct }\end{array}$ \\
\hline 7 & $\begin{array}{l}\text { Opaque } \\
\text { amniotic } \\
\text { membranes }\end{array}$ & Agreed 7 & $\begin{array}{l}1 \text { Funisitis } \\
2 \text { Micro calcifications } \\
2 \text { Meconium stain }\end{array}$ \\
\hline 6 & $\begin{array}{l}\text { Long } \\
\text { umbilical } \\
\text { cord }\end{array}$ & $\begin{array}{l}\text { Agreed } 6 \\
\text { Mean length } \\
112 \mathrm{~cm}(103-120)\end{array}$ & $\begin{array}{l}1 \text { Funisitis } \\
1 \text { Vasculopathy }\end{array}$ \\
\hline 6 & $\begin{array}{l}\text { Foul smelling } \\
\text { amniotic } \\
\text { membranes }\end{array}$ & Agreed 5 & $\begin{array}{l}5 \text { Chorioamniotis } \\
1 \text { Meconium stain }\end{array}$ \\
\hline 4 & $\begin{array}{l}\text { Short } \\
\text { umbilical cord }\end{array}$ & $\begin{array}{l}\text { Agreed } 2 \\
\text { (clots not seen at } \\
\text { examination) }\end{array}$ & $\begin{array}{l}1 \text { Old infarct } \\
1 \text { Micro calcifications } \\
2 \text { Fibrin deposits }\end{array}$ \\
\hline 4 & $\begin{array}{l}\text { Retro } \\
\text { placental } \\
\text { hemorrhage }\end{array}$ & Agreed 4 & None \\
\hline 2 & $\begin{array}{l}\text { Acute } \\
\text { abruption }\end{array}$ & Agreed 2 & 1 Recent infarct \\
\hline 7 & Normal & Agreed 7 & $\begin{array}{l}2 \text { Chorioamniontis } \\
1 \text { Mecomium stain } \\
3 \text { Fibrin deposits } \\
1 \text { Funisitis }\end{array}$ \\
\hline
\end{tabular}

gies of immediate insults requiring delivery, as well as a timeline of chronic events leading to fetal intolerance to labor. In placental pathology, few diagnoses are immediately apparent: generally only those, which are hematogenously disseminated, like infectious organisms or some specific inborn errors of metabolism. However, on closer examination, histopathological evidence of choriamniontiis including one specific finding of umbilical cord inflammation (funisitis) is associated with fetal sepsis.

According to Rhone et al., in review of 100 sequential placentas, $75 \%$ were submitted to pathology for review by CAP protocol with $50 \%$ having findings consistent with inflammation [4]. Fetal clinical indicators of infection were associated with placental findings of chorioamnionitis, while maternal clinical indicators were not, emphasizing the utility of placental examination in identifying unknown material infection.

Also of interest are pathological findings of endothelial damage to fetal vessels secondary to infection or vascular insults in the placenta resulting in fetal side infarctions that can be a hallmark of neonatal embolic 
disease. Roberts et al. [5] reported that "fetal thrombotic vasculopathy," referring to inflammatory damages to vessels secondary to infection or vascular insult and related placental findings is often cited in a legal context [6-8], however, further research is need to determine prognostically how these findings affect long-term neonatal outcome.

Our study found $35 \%$ of placentas with gross abnormalities associated with potential for adverse fetal consequences including opaque or foul smelling amniotic membranes; velamentous cord insertion, long umbilical cord, and short umbilical cord, acute abruption, and retro placental hemorrhage. Additionally 7 placentas (7\%) were reported to be abnormal at the pathology examination as follow: chorioamnionitis, funisitis, and true knots. Such abnormalities were associated with reassuring neonatal outcomes as measured by APGAR scores of more than 7 at 5 minutes of birth, normal arterial and venous umbilical blood cord gases and uneventful nursery stay. What is unknown is the degree to which these placental anomalies, while not associated with abnormal fetal development, effect placental perfusion, leading to fetal intolerance of labor.

A recent classification system of cerebral palsy calls for an assessment of the timing and etiology of brain injury [9]. The placental examination is an underused resource for addressing these important questions. An expert assessment of the placental pathology can provide temporally and mechanistically specific data not available from any other source. An analysis of 125 placentas from term infants with cerebral palsy, neonatal encephalopathy, and other neurodisabilities compared with 200 term placentas from healthy infants, found four lesions: fetal thrombotic vasculopathy, chronic villitis with obliterative vasculopathy, chorioamnionitis with intense chorionic vasculitis, and meconium associated vascular necrosis to be statistically significantly increased in affected infants when controlled for confounding factors. Further analysis demonstrated that the lesions were equally common in affected infants with normal or abnormal umbilical blood gases and 5 min APGAR scores [10]. While this data is limited, it does demonstrate a placental abnormality as seen on histological examination as correlated with neonatal outcome.

\section{Comments}

The prevalence of abnormal placental findings in our studied population was $42 \%$. Placental anomalies could contribute to non-reassuring tracings that require emergent delivery. Further delineation of specific placental abnormalities in relationship to adverse neonatal outcomes requires increased collaboration between Obstetricians, Pathologists, and Neonatologists with diligent analysis of placentas both grossly and histologically.

\section{Key Points}

- All human placentas should be inspected and triaged at the delivery room and the abnormal ones should be sent to pathology for a complete examination

- The placenta provides a third party perspective regarding the pregnancy and many maternal and fetal conditions are evidenced by placental abnormalities.

- Placental anomalies could contribute to non-reassuring tracings that require emergent delivery.

- The prevalence of abnormal placental findings in our studied population was $42 \%$

- The most common pathologies were marginal core insertion, chorioamnionitis and abruption

\section{REFERENCES}

[1] S. Aladjem, E. Perrin and A. Fanaroff, "Placental Score and Neonatal Outcome: A Clinical and Pathologic Study," Obstetrics and Gynecology, Vol. 39, No. 4, 1972, pp. 591-602.

[2] A. L. Kent and J. E. Dahlstrom, "Placental Assessment: Simple Techniques to Enhance Best Practice," Australian and New Zealand Journal of Obstetrics and Gynaecology, Vol. 46, No. 1, 2006, pp. 32-37. doi:10.1111/j.1479-828X.2006.00511.x

[3] G. Ventolini, R. Samlowski and D. L. Hood, "Placental Findings in Low-Risk, Singleton, Term Pregnancies after Uncomplicated Deliveries," American Journal of Perinatology, Vol. 21, No. 6, 2004, pp. 325-328.

doi:10.1055/s-2004-831882

[4] S. A. Rhone, F. Magee, V. Remple and D. Money, "The Association of Placental Abnormalities with Maternal and Neonatal Clinical Findings: A Retrospective Cohort Study," Journal of Obstetrics and Gynaecology Canada, Vol. 25, No. 2, 2003, pp. 123-128.

[5] D. Roberts and E. Oliva, "Clinical Significance of Placental Examination in Perinatal Medicine," The Journal of Maternal-Fetal and Neonatal Medicine, Vol. 19, No. 5, 2006, pp. 255-264. doi:10.1080/14767050600676349

[6] K. Benirschke, "The Placenta in the Litigation Process," American Journal of Obstetrics and Gynecology, Vol. 162, No. 6, pp. 1445-1450.

[7] F. T. Kraus, "Perinatal Pathology, the Placenta, and Litigation," Humam Pathology, Vol. 34, No. 6, 2003, pp. 517-521. doi:10.1016/S0046-8177(03)00227-2

[8] J. P. Lavery, "The Role of Placental Examination and Its Pathology in Obstetric Risk Management," Journal Healthcare Risk Management, Vol. 17, No. 3, 1997, pp. 15-20. doi:10.1002/jhrm.5600170304

[9] R. W. Redline, "Placental Pathology and Cerebral Palsy," Clinics in Perinatology, Vol. 33, No. 2, 2006, pp. 503516. doi:10.1016/j.clp.2006.03.007

[10] R. W. Redline, D. Heller, S. Keating and J. Kingdom, "Placental Diagnostic Criteria and Clinical CorrelationA Workshop Report," Placenta, Vol. SA, 2005, pp. S114S117. 